\title{
DYESTUFFS AND FORMALDEHYDE CONTENT IN SPLIT LEATHER TREATED WITH FORMALDEHYDE RESINS
}

\author{
Agustí Marsal $^{\text {* }}$, Sara Cuadros ${ }^{\mathrm{a}}$, Rosa M. Cuadros ${ }^{\mathrm{b}}$, Joaquim Font $^{\mathrm{b}}$, Albert M$^{\mathrm{a}}$ Manich $^{\mathrm{a}}$ \\ anstituto de Química Avanzada de Cataluña, IQAC-CSIC, C/ Jordi Girona 18-26, \\ Barcelona, Spain
}

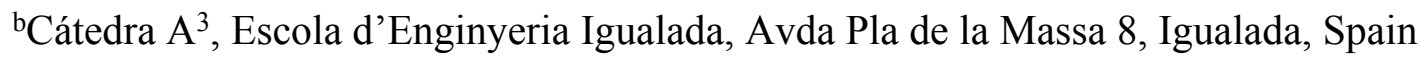

\begin{abstract}
Formaldehyde resins are present in textile, leather and wood industries. Due to the harmful character of formaldehyde, different alternatives have been found to exclude or reduce its content on processed goods. However, the effect of dyestuffs on the formaldehyde content of goods containing formaldehyde-synthesized resins has not been studied up to date. The aim of this work is to check if the presence of free amino groups in the structure of dyestuffs exerts an influence on the formaldehyde content on leathers treated with formaldehyde-synthesized resins. Six dyes, belonging to three different families (acid dyes, direct dyes and basic dyes), have been taken as examples to evaluate how their structures affect the reaction with formaldehyde present in leather. The variation of the formaldehyde content in dyed leathers with respect to control samples (treated with resin only) and its evolution with time have been also considered.

It has been found that the ability of dyes in reducing the formaldehyde content in leather depends on the amount of amino groups amenable to reaction with formaldehyde. Those amino groups that in their vicinity have other functionalities, with which to form relatively stable structures, have a reduced reactivity with formaldehyde.

The reduction ability of dyes also depends on the formaldehyde content in leather. The lower the formaldehyde content is in the leather, the higher this reduction ability. Acid Black 234 dye caused a formaldehyde content reduction of approximately $84 \%$ in leathers treated with melamine-formaldehyde resin of low formaldehyde content in the analysis carried out after 90 days of leather processing whereas the reduction was approximately $20 \%$ when the resin was of high formaldehyde content.
\end{abstract}


The highest reduction ability of basic dyes corresponded to the dye that has the greatest amount of amino residues amenable to reaction with formaldehyde (Basic Orange 2). Basic Orange 2 dye exhibited higher reduction ability (90\% of reduction in leathers treated with resin of high formaldehyde content after 90 days of leather processing) than the Acid Black 234 dye (approximately 20\%), both containing similar amount of free amino residues. Thin layer chromatography analysis revealed that the Basic Orange 2 dye is mainly a single major component, while the Acid Black dye 234 is a mixture of components that can have a reduced reactivity with formaldehyde. Further experiments are required to investigate if the surface leather dyeing (Basic Orange 2 dye) have a higher influence on formaldehyde content reduction than the through-dyeing (Acid Black 234 dye).

Keywords: dyes-formaldehyde interaction; acid/basic dyes; formaldehyde resins; formaldehyde content reduction; leather, textile, wood industries.

*Corresponding author. Fax: +34 932045904

E-mail address: agusti.marsal@iqac.csic.es (A. Marsal) 


\section{Introduction}

Many international organizations encourage the implementation of cleaner technologies in leather and textile processing [1,2,3]. These cleaner technologies must be developed to prevent the presence of some restricted chemicals, which take part in the formulation of commercial products used at various stages of the tannery processes. Due to its carcinogenic character [4, 5], formaldehyde is one of these chemicals included in the "restricted substances list" of major brands.

Different alternatives have been proposed to exclude the presence of formaldehyde in leather: use of protein or acrylic syntans $[6,7]$, or to reduce its content to allowed levels: application of formaldehyde scavengers for leather substrate [8] or for wood substrate $[9,10]$. In a previous study [11], the ability of four scavengers (ethylene urea, pyrogallol, gallic acid and hydroxylamine sulphate) on reducing the formaldehyde content in leathers treated with formaldehyde resins was studied. The authors found that, although the four chemicals reduce at different extent the formaldehyde content, some of they have certain disadvantages

Other authors have proposed the use of plant extracts to reduce the formaldehyde content in leathers pre-tanned with formaldehyde $[12,13]$ or the addition of plant extracts to urea-formaldehyde resins to reduce the emission of formaldehyde from panels of medium density fibreboard [14]. The effect of the polyphenols (tannins and non-tannins) contained in some vegetable compounds (mimosa, quebracho and tara), normally used in tanning/retanning processes, on the reduction of formaldehyde content in leathers treated with formaldehyde-synthesized resins has been also studied [15]. The authors found that the high reactivity of the polyphenols of the mimosa extract towards formaldehyde led to the highest reduction of the formaldehyde content and that this capacity was accentuated with ageing.

However, no work has been found in literature dealing with the interaction formaldehyde- leather dyeing. How dyestuffs can interact with formaldehyde present in leather has not been studied.

Leather is dyed to improve its appearance, to make it adaptable for fashion styling and to increase its value as a commodity. Dyestuffs suitable for leather may be grouped into anionic and cationic types. Anionic dyes are alkali salts of dye acids; cationic dyes 
(known as basic dyes) are the acid salts of dye bases [16]. Anionic dyes constitute the greater portion of the dyes used for leather and include acid dyes, direct dyes, mordant dyes and metal complex dyes.

The aim of this work is to study the possible effect of the dyeing process on the formaldehyde content in split leather treated with formaldehyde resins. In particular, the work is focused to investigate if the presence of free amino groups in the dye structure causes a reduction in the formaldehyde content of leather treated with formaldehydesynthesized resins. The authors believe that the reaction between the amino groups of the dyes and formaldehyde may decrease the formaldehyde content in leather. The evolution of formaldehyde content with time and its variation with respect to the samples treated with resin only (control samples) are also considered.

\section{Materials and methods}

\subsection{Materials}

\subsubsection{Starting material: split leather}

Butts of wet-blue splits shaved to a thickness of $1.5 \mathrm{~mm}$ of German origin supplied by Despell S.A. were used as the starting material. This starting material is characterized by its homogeneity which minimizes the variation in chemicals absorption, facilitating their penetration.

\subsubsection{Formaldehyde-based resins}

The resins used in this study are the same as those employed in previous works $[11,15]$. They result from the condensation reaction between formaldehyde with melamine (MF) and dicyandiamide (DCDF). Resins were selected as a function of their formaldehyde content: low formaldehyde content (termed A) and high formaldehyde content (termed B) and were used one or another depending on the experiment. The formaldehyde content in the resins were analysed in accordance with the method described in Section 2.2.3, providing the following mean values $\pm 95 \%$ confidence intervals of five replicates: $\mathrm{MF}(\mathrm{A}): 4514 \pm 326 \mathrm{mg} / \mathrm{kg} ; \operatorname{DCDF}(\mathrm{A}): 6428 \pm 466 \mathrm{mg} / \mathrm{kg}$ and $\mathrm{MF}(\mathrm{B}):$ $23481 \pm 369 \mathrm{mg} / \mathrm{kg}$. 


\subsubsection{Dyes employed}

The influence of six dyes belonging to three different families (acid dyes, direct dyes and basic dyes) on the formaldehyde content in split leather treated with formaldehyde resins was studied.

Acid Dyes derive their affinity entirely from acid groups within the molecule and behave quite similarly to moderately strong acids. The acid dyes studied in this work are: Acid Red 337 (Colour Index: 17102); Acid Brown 83 (Colour Index: 20250) and Acid Black 234 (Colour Index: 30027).

Direct dyes are also known as cotton dyes. They can be used on cotton fibres without a mordant. The term direct has little significance in chrome leather dyeing. These dyes are generally more of the surface dyeing than acid type. Direct Black 168 (Colour Index: 30420) has been considered in this study.

Basic dyes (called cationic dyes) are applied to substrate with anionic character where electrostatic attractions are formed. They are called cationic dyes because the chromophore in basic dye molecules contains a positive charge. The basic dyes react on the basic side of the isoelectric points. As examples of basic dyes, Basic Brown 1 (Colour Index: 21000:1) and Basic Orange 2 (Colour Index: 11270) have been taken in this study.

All dyes were supplied by Trumpler Española S.A., and they were applied following its recommendations. Figure 1 shows the chemical structure of the dyes considered in this work.

(Figure 1)

\subsection{Methods}

\subsubsection{Processing of leathers. Experiments carried out}

Once received from the tannery, all the splits were subjected to a common process of rechroming and neutralization up to $\mathrm{pH}$ of 5.2-5.4 as shown in Table 1. Retanning was carried out with a $3 \%$ of a commercial acrylic resin and $5 \%$ of formaldehydesynthesized resins. Depending on the formaldehyde content of the resins, two series of experiments were performed: i) Dyeing treatments of splits treated with resins of low 
formaldehyde content ((MF (A) and DCDF (A)) and ii) Dyeing treatments of splits treated with resins of high formaldehyde content ((MF (B) and DCDF (B)). The goal was to determine the effect that different dyes had on the formaldehyde content in leathers treated with resins of different formaldehyde content. After dyeing, a conventional fatliquoring process was carried out with chemicals of common use in the leather industry, supplied by Pulcra Chemical S.L. Once treated in accordance with the formulation of Table 1 and after drying, the leathers were analysed for formaldehyde content in accordance with the EN ISO 17226 Standard. Part 2 [17]. Given that in a previous work [15], it was found that the formaldehyde content in leathers treated with formaldehyde resins and retanned with vegetable compounds varied with ageing, analyses were performed at different times after leather processing. During this period, the samples for analysis were maintained in the dark, inside airtight plastic bags, in a standard atmosphere at $23^{\circ} \mathrm{C}$ and $50 \%$ relative humidity [18] to have them always at the same conditions.

\section{(Table 1)}

\subsubsection{Analysis of formaldehyde content in leather}

The formaldehyde content in split leathers was determined in accordance with the EN ISO 17226 Standard. Part 2 [17]. Given that the method described in the Standard is a little bit ambiguous, it is very important to clearly define the conditions of the extraction of formaldehyde from leather. The results of formaldehyde content in leather depend on the shaking method used in the extraction [19], therefore, this should be clearly described. The leather was extracted by gently shaken $(40 \pm 1 \mathrm{rpm})$ in a reciprocal linear shaker (Selecta, Unitronic) with a $0.1 \%$ solution of sodium dodecyl sulphate. In a previous work [20], it was found that this surfactant gave similar results to those obtained with the more expensive sodium dodecyl sulphonate, which is suggested by the Standard. No variations were made, relative to the Standard, on the quantitative determination of the extracted formaldehyde through the reaction with acetylacetone.

The experimental results of formaldehyde content for each treatment, shown in Tables 3 and 4 , are the mean value of six measurements corresponding to three replicates for each of two analysed samples. 


\subsubsection{Analysis of formaldehyde content in formaldehyde resins}

The determination of the formaldehyde content in the formaldehyde-synthesized resins was performed following an adaptation of the EN ISO 17226 Standard. Part 1 [21]. The quantification of the formaldehyde extracted from the resin with sodium dodecyl sulphate solution was carried out by HPLC after reaction with dinitrophenylhydrazine. Five replicates of the analysis of formaldehyde content in the resins were performed.

\subsubsection{Determination of the inorganic matter in dyestuffs}

Given that there is no official method for the determination of inorganic matter in dyes, this analysis was performed following the EN ISO 4047 Standard [22] with modifications. A given amount of the dyestuff $(2 \mathrm{~g})$ was carefully burnt over a low flame (Bunsen) in an open crucible until fumes were no longer visible. Afterwards, the crucibles were placed in a muffle furnace set to $550{ }^{\circ} \mathrm{C}$ for 6 hours until complete ashing, cooled in the desiccator and weighed. The mean values $\pm 95 \%$ confidence intervals of three replicates of the inorganic matter (salts) percentage in the dyes are shown in Table 2.

From the number of $\mathrm{NH}_{2}$ groups present in the dyes structure, the amount of dye offered and the percentage of inorganic matter in dye formulations, it was possible to estimate the amount of amino residues given for a quantity of leather (100 g) (Table 2).

\section{(Table 2)}

\subsubsection{Thin layer chromatography of dyestuffs}

In order to check if in the dye manufacturing process a single major component was produced or was a mixture of components, thin layer chromatography (TLC) of several dyes (Acid Black 234, Basic Brown 1 and Basic Orange 2) was carried out by using silica gel $60 \mathrm{~F}_{254}$ plates (Merck, ref. 1.05554.0001). $50 \mu \mathrm{L}$ of a $1 \%$ dye solution were placed at the starting point of the plates and were developed by using the following solvents: n-butanol, $20 \mathrm{~mL}$; glacial acetic acid, $10 \mathrm{~mL}$; distilled water, $50 \mathrm{~mL}$ for basic dyes; and n-butanol, $15 \mathrm{~mL}$; acetone, $15 \mathrm{~mL}$; $25 \%$ ammonia, $6 \mathrm{~mL}$; distilled water, 3 $\mathrm{mL}$ for acid dyes. The results obtained are shown in Section 4 (Figure 10).

TLC analysis was carried out by Trumpler Española S.A. 


\subsubsection{Regression Analysis}

The variation with time of formaldehyde content in leathers treated with formaldehyderesins with/without dyeing has been estimated by means of a linear regression analysis. Table 3 (for resins of low formaldehyde content) and Table 4 (for resins of high formaldehyde content) show the results of the initial formaldehyde content, $[\mathbf{F C}]_{0}$, and the rate of variation in content, $[\mathbf{F C}]_{\text {rate }}$, as a function of the number of days elapsed after leather treatment ND, together with the correlation coefficient, $\mathbf{r}$, of the fitted linear regression $[\mathrm{FC}]=[\mathrm{FC}]_{0}+[\mathrm{FC}]_{\text {rate }} \times \mathrm{ND}$. Both tables also include the $95 \%$ confidence interval of the regression coefficients. For each point of the regression lines, the formaldehyde content is the average of six measurements.

\section{Results}

\subsection{Treatments with resins of low formaldehyde content}

Figure 2 shows the formaldehyde content as a function of the number of days elapsed after treatments in leathers retanned with MF (A) resin and dyed with 4\% of Acid Black 234 and Acid Red 337 and without dyeing (control samples).

\section{(Figure 2)}

To determine with more precision the variation in formaldehyde content [FC] with the number of days ND elapsed after treatment, the two split leather retanned with MF (A) resin without dyeing (control samples) were grouped. Table 3 shows the linear regression analysis of the formaldehyde content versus time (see Section 2.2.6).

\section{(Table 3)}

For the control samples, the variation of formaldehyde content with time resulted in a growth of $+0.20 \pm 0.04 \mathrm{mg} / \mathrm{kg}$ of formaldehyde per day elapsed after treatment. As reported in a previous study [15], the increase in formaldehyde content with time could indicate that, besides free formaldehyde due to an excess in the resin preparation process, the resin is progressively hydrolysed.

The dyeing process with $4 \%$ of Acid Black 234 resulted in a decrease in the initial formaldehyde content from $51.51 \pm 4.86$ to $17.77 \pm 4.20 \mathrm{mg} / \mathrm{kg}$ while the reduction rate was not significantly different from zero $(-0.04 \pm 0.06 \mathrm{mg} / \mathrm{kg}$ per day elapsed). When 4 
$\%$ of Acid Red 337 was employed in dyeing, a slight reduction in the rate of increase of formaldehyde content with time $(+0.10 \pm 0.06 \mathrm{mg} / \mathrm{kg})$ took place. The difference between the regression equations for undyed leathers (only retanned with MF (A)) and for those dyed with a 4\% of Acid Red 337 was significant at 5\% [23]. The Acid Black 234 dye showed a greater ability than the Acid Red 337 dye in reducing the formaldehyde content in dyed leathers.

By comparing the results of formaldehyde content for each different dye with those of its reference (undyed samples), it was possible to determine the reductions in formaldehyde content (in \%) by applying the following equation at each time of the analysis:

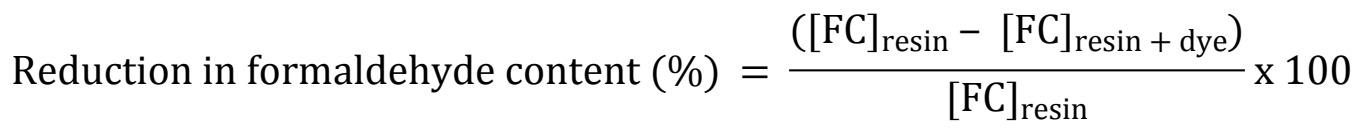

Figure 3 shows the variation of the reduction of formaldehyde content with time. The formaldehyde content reduction in leathers dyed with Acid Black 234 dye was important even a few days after leather processing. This is why the reduction rate was only of $-0.04 \pm 0.06 \mathrm{mg} / \mathrm{kg}$ per day elapsed. The reduction varied from $58 \%$ at 7.5 days after treatment to $88 \%$ at 203 days elapsed. Given that the formaldehyde content of the control samples ((only retanned with MF (A)) increased with ageing and that of samples dyed with Acid Black 234 dye decreased (Figure 2), the reduction in formaldehyde content, which is the difference between the two values, grew with the time elapsed after treatments. The Acid Red 337 dye showed a poor capacity for reducing the formaldehyde content of leathers treated with MF (A) resin. A reduction of the formaldehyde content of approximately 15\% was observed from the analyses performed at 90 days post treatment. However, this was rather due to the increase in the formaldehyde content of the control samples than to the reduction ability of the Acid Red 337 dye.

\section{(Figure 3)}

When results of formaldehyde content in leathers retanned with DCDF (A) resin and dyed with 4\% of Acid Black 234 and Acid Red 337 and without dyeing (control samples) are examined, the same trends as those observed for the MF (A) resin were obtained (Figure 4). 
(Figure 4)

As in the case of MF (A), the results for the two leathers retanned with DCDF (A) resin without dyeing (control samples) were grouped to obtain a higher precision in the determination of formaldehyde content as a function of the number of days elapsed. By comparing Figures 2 and 4, the formaldehyde content in leather retanned with DCDF (A) was lower than that of MF (A) treated splits. As observed in Table 3, the initial formaldehyde content for leathers treated with DCDF (A) resin was $34.49 \pm 2.51 \mathrm{mg} / \mathrm{kg}$ while it was $51.51 \pm 4.86$ when MF (A) resin was used. The growth rate of formaldehyde content per day elapsed after treatment was reduced between two and three times $(+0.07 \pm 0.02$ vs. $+0.20 \pm 0.04 \mathrm{mg} / \mathrm{kg})$. This increase of formaldehyde content with time indicates that the DCDF (A) resin is progressively hydrolysed.

When the effect of the dyeing process on the formaldehyde content in leathers retanned with DCDF (A) resin is examined, Table 3 shows that a 4(\%) of the Acid Black 234 dye led to a drastic decrease in the formaldehyde content from the beginning. The initial formaldehyde content decreased from $34.49 \pm 2.51 \mathrm{mg} / \mathrm{kg}$ to $6.67 \pm 1.53 \mathrm{mg} / \mathrm{kg}$. Given that the reduction rate $(-0.02 \pm 0.03 \mathrm{mg} / \mathrm{kg})$ was not significantly different from zero, it can be considered that the formaldehyde content was practically constant with time. For leathers dyed with the Acid Red 337 dye, the initial formaldehyde content was similar to that of the control samples (retanned with DCDF (A) resin without dyeing) and this dye did not significantly modify the formaldehyde content with time, with a reduction rate of $-0.01 \pm 0.03 \mathrm{mg} / \mathrm{kg}$ per day elapsed.

Figure 5 shows the reduction in formaldehyde content when samples retanned with DCDF (A) resin and dyed with Acid Black 234 and Acid Red 337 dyes are compared to control samples without dyeing. Most likely, due to the lower formaldehyde content in leathers retanned with DCDF (A) (Figure 4) than those with MF (A) (Figure 2), the effect of dyeing was a little bit more accentuated. However, the same trends were observed in the splits retanned with both resins. The effect of dyeing with Acid Black 234 resulted in a reduction of the formaldehyde content that varied from $75 \%$ (analysis performed at 7 days after treatments) to $92 \%$ (analysis carried out at 204 days after treatments). The Acid Red 337 dye caused a formaldehyde content reduction that was much less marked than that of the Acid Black 234 dye. A $31.5 \%$ was the highest reduction that occurred after 204 days of leather processing. However, given that the 
formaldehyde content of leathers dyed with the Acid Red 337 dye was almost constant over time (Figure 4), the progressive increase in the reduction of formaldehyde content up to $31.5 \%$ was due to the progressive increase in the formaldehyde content of the control samples (without dyeing).

\section{(Figure 5)}

The Acid Black 234 dye showed an ability in reducing the formaldehyde content in leathers retanned with low formaldehyde content resins ((MF (A) and DCDF (A)) that was much higher than that of the Acid Red 337 dye. This reduction ability was more remarkable for lower formaldehyde content in the treated leathers (retanned with DCDF (A) resin).

\subsection{Treatments with resins of high formaldehyde content}

The formaldehyde content in splits retanned with MF (B) resin and dyed with $4 \%$ of Acid Black 234, Direct Black 168 and Acid Brown 83 and without dyeing (control samples) as a function of the number of days elapsed after treatments can be observed in Figure 6. Given that the Acid Red 337 dye showed a much lower ability than the Acid Black 234 dye in reducing the formaldehyde content in leathers retanned with low formaldehyde content resins ((MF (A) and DCDF (A)), its study was discarded. As mentioned in Section 3.1, the same tendencies were observed in the samples retanned with ((MF (A) and DCDF (A)) and dyed with Acid Black 234 and Acid Red 337 dyes, therefore, only the use of MF resin with a high formaldehyde content, MF (B), has been considered.

The three leathers retanned with MF (B) resin without dyeing (control samples) were grouped in order to determine with more precision the variation of formaldehyde content $[\mathrm{FC}]$ with the number of days ND elapsed after treatment. Figure 6 shows that the formaldehyde contents in leathers treated with $\mathrm{MF}(\mathrm{B})$ resin were higher than those treated with MF (A) resin (Figure 2).

\section{(Figure 6)}

The results of the regression analysis are shown in Table 4. The initial formaldehyde content $\left([\mathrm{FC}]_{0}\right)$ of the control samples retanned with MF (B) resin (without dyeing) was more than four times $(218.04 \pm 8.61 \mathrm{mg} / \mathrm{kg})$ that of samples treated with MF (A) resin 
$(51.51 \pm 4.86 \mathrm{mg} / \mathrm{kg}$, Table 3). As with the MF (A) resin, the formaldehyde content in leathers retanned with the MF (B) resin increased progressively with time. The rate of increase, $\left([\mathrm{FC}]_{\text {rate }}\right)$, was similar for both resins: $+0.19 \pm 0.08 \mathrm{mg} / \mathrm{kg}$ for the MF (B) resin (Table 4) and $+0.20 \pm 0.04 \mathrm{mg} / \mathrm{kg}$ for the MF (A) resin (Table 3). The dyeing operation carried out with the Acid Black 234 (4\%) led to a decrease in the initial formaldehyde content of leathers retanned with MF (B) resin from $218.04 \pm 8.61 \mathrm{mg} / \mathrm{kg}$ to $177.23 \pm 13.38 \mathrm{mg} / \mathrm{kg}$. This decrease was much less marked than when MF (A) resin was used as a retanning agent. Unlike the formaldehyde content in samples retanned with MF (A) and dyed with Acid Black 234 that remained practically constant over time, when $\mathrm{MF}(\mathrm{B})$ was employed, the formaldehyde content increased as the days elapsed after treatments $\left([\mathrm{FC}]_{\text {rate }}=+0.24 \pm 0.12 \mathrm{mg} / \mathrm{kg}\right)$. Most likely, this different behaviour of the Acid Black 234 dye was due to the higher formaldehyde content of the MF (B) resin. The effects of dyeing with 4\% of Acid Black 234 or Direct Black 168 on the formaldehyde content of leathers retanned with MF (B) resin were similar so that no significant differences between their regression equations were observed [23]. The effect of dyeing with Acid Brown 83 on the reduction of formaldehyde content was less marked than that of the other two dyes. The initial formaldehyde content decreased from $218.04 \pm 8.61 \mathrm{mg} / \mathrm{kg}$ (control samples) to $197.28 \pm 12.39 \mathrm{mg} / \mathrm{kg}$. Given that the variation rate $(+0.07 \pm 0.11 \mathrm{mg} / \mathrm{kg})$ was not significantly different from zero, it can be considered that the formaldehyde content was practically constant with time.

\section{(Table 4)}

Figure 7 shows the reduction in formaldehyde content when split samples dyed with Acid Black 234, Direct Black 168 and Acid Brown 83 dyes are compared to control samples without dyeing. The differences between the three dyes were very small. As can be seen, in none of the three cases a reduction of the formaldehyde content above $30 \%$ was achieved. The fact that the reduction of the formaldehyde content was almost constant over time was due to that the formaldehyde content of both dyed and non-dyed samples increased progressively.

In contrast, the effect of dyeing with Acid Black 234 on the reduction of the formaldehyde content in leathers retanned with MF (A) (Figure 3) was much higher (reduction of approximately $84 \%$ at 89.5 days after treatments).

(Figure 7) 


\subsection{Treatments with basic dyes}

The influence of two basic dyes (Basic Brown 1 and Basic Orange 2) on the formaldehyde content of splits retanned with MF resin of high formaldehyde content (MF (B)) was determined. Both dyes were applied at an offer of $0.75 \%$ on shaved wetblue weight. Formulation shown in Table 1 with a modification was followed. Dyeing process was not carried out before fatliquoring as mentioned in Table 1. Dyes were applied after fatliquoring, fixing with formic acid and washing with water. For dye application, dyes were pasted with ethanol, water and acetic acid to increase solubility.

Figure 8 shows the formaldehyde content in leathers retanned with MF (B) resin and dyed with $0.75 \%$ of Basic Brown 1 and Basic Orange 2 and without dyeing (control samples) as a function of the number of days elapsed after treatments.

\section{(Figure 8)}

The results of the regression analysis are shown in Table 4. The initial formaldehyde content $\left([\mathrm{FC}]_{0}\right)$ of the control samples retanned with MF (B) resin (without dyeing) was $211.86 \pm 20.16$ with an increasing rate, $\left([\mathrm{FC}]_{\text {rate }}\right.$ ), of $+0.37 \pm 0.17 \mathrm{mg} / \mathrm{kg}$. Once again the progressive hydrolysis of resins synthesized with formaldehyde is confirmed. The application of $0.75 \%$ of Basic Brown 1 resulted in a decrease of the initial formaldehyde content, $\left([\mathrm{FC}]_{0}\right.$ ), from $211.86 \pm 20.16 \mathrm{mg} / \mathrm{kg}$ (control samples without dyeing) to $65.09 \pm 7.58 \mathrm{mg} / \mathrm{kg}$. This highlights the high capacity of the Basic Brown 1 dye in reducing the formaldehyde content in leathers retanned with formaldehyde-synthesized resins. The variation rate, ([FC $\left.]_{\text {rate }}\right)$, was $+0.22 \pm 0.06 \mathrm{mg} / \mathrm{kg}$, i.e., an increase of formaldehyde content per day elapsed after treatments significantly lower than that of the control samples $(+0.37 \pm 0.17 \mathrm{mg} / \mathrm{kg})$. Most likely, this means that the ability of Basic Brown 1 is not sufficient to fully compensate for the increase in formaldehyde content due to the resin hydrolysis. Much more pronounced was the diminution in the initial formaldehyde content due to the application of a $0.75 \%$ of Basic Orange 2 since the $\left([\mathrm{FC}]_{0}\right)$ dropped to $25.51 \pm 9.35 \mathrm{mg} / \mathrm{kg}$. Although formaldehyde content tended to increase as a function of the time elapsed after treatments, the variation rate $(+0.09 \pm 0.08$ $\mathrm{mg} / \mathrm{kg}$ ) was not significantly different from zero.

Figure 9 shows the reduction in formaldehyde content when leather samples dyed with Basic Brown 1 and Basic Orange 2 were compared to control samples without dyeing as 
a function of the number of days elapsed after treatments. As observed, the ability of the Basic Orange 2 dye in reducing the formaldehyde content in leather treated with MF (B) resin was higher than that of the Basic Brown 1. For the Basic Brown 1 dye, the maximum reduction of formaldehyde content (approx. $70 \%$ ) was reached at 30 days after treatments whereas for the Basic Orange 2 dye the maximum reduction was approx. $90 \%$ after 90 days. After these periods of time, the reduction of the formaldehyde content due to both dyes decreased to approximately $62 \%$ and $84 \%$ for Basic Brown 1 and Basic Orange 2, respectively at 170 days after the treatments. This decrease that is observed in the reduction of formaldehyde content after a long time of the treatments (170 days) is mainly due to the pronounced increase in the formaldehyde content that occurs due to the hydrolysis of the resin or to certain reversibility of the reaction between the $\mathrm{NH}_{2}$ groups of the dyes and the formaldehyde as observed in the case of hydroxylamine sulfate [11].

\section{(Figure 9)}

It should be emphasized that although the application of dyes such as Acid Black 234, Direct Black 168 and Acid Brown 83 gave rise to a maximum formaldehyde content reduction of the $30 \%$ (Figure 7) in leathers retanned with MF (B) resin, the use of dyes such as Basic Brown 1 and Basic Orange 2 resulted in reductions of up to $70 \%$ and $90 \%$ respectively, as seen in Figure 9.

\section{Discussion}

The decrease in the formaldehyde content in leather retanned with formaldehydesynthesized resins by the dyeing process could be explained by the reaction between formaldehyde and the amino groups present in the dyes structure. It should be noted that the extent of this decrease is a function not only of the number of the amino groups present in the dyes but also of their relative reactivity with formaldehyde. The vicinity of other functionalities, such as $-\mathrm{OH},-\mathrm{N}=\mathrm{N}-$ and $-\mathrm{NO}_{2}$, to the amino groups can lead to the formation of relatively stable cyclic structures mediated by hydrogen bonds. When this occurs, the reactivity of this amino group with formaldehyde can decrease.

In the treatments carried out with resins of low formaldehyde content ((MF (A) and DCDF (A)), the Acid Black 234 dye exhibited higher reduction ability of the formaldehyde content than the ability of the Acid Red 337 dye. This is most likely 
related to the greater amount of amino residues provided by the Acid Black 234 dye for a certain quantity of leather (see Table 2). The structure of the Acid Black 234 dye has three $\mathrm{NH}_{2}$ groups. Two of them may have a reduced reactivity with formaldehyde because of the proximity of one $-\mathrm{OH}$ group, in one case, and one $-\mathrm{N}=\mathrm{N}$ - group in the other case. Therefore, the Acid Black 234 dye has one completely free $\mathrm{NH}_{2}$ group to react with formaldehyde. The structure of the Acid Red 337 dye has only one $\mathrm{NH}_{2}$ group with a $-\mathrm{N}=\mathrm{N}$ - group very close to it. Therefore, due to the proximity between both groups, the formation of a relatively stable cyclic structure is possible resulting in a decreased reactivity with formaldehyde. So, the Acid Red 337 dye has no one free $\mathrm{NH}_{2}$ group to react with formaldehyde. Although similar trends were observed, the effect of both dyes was a little more pronounced when DCDF (A) resin was used due to the lower formaldehyde content in leathers treated with this resin.

When a resin with high formaldehyde content (MF (B)) was used, the ability of the Acid Black 234 was, in percentage, much lower than with the resins with low formaldehyde content. Most likely, the diminution capacity of the dye is not sufficient to totally compensate the marked increase in formaldehyde content resulting from resin hydrolysis. To achieve a reduction in the formaldehyde content in a higher percentage, the dyeing process should be carried out with a greater offer of dyestuff, which is not industrially advisable. In the treatments carried out with the other two dyes (Direct Black 168 and Acid Brown 83), reductions in formaldehyde content greater than $30 \%$ were not obtained. It is important to note that completely free amino groups amenable to reaction with formaldehyde are not present in both dyes (see Table 2). As observed in Figure 1, the Direct Black 168 dye has two amino groups that may have a reduced reactivity with formaldehyde due to the proximity of an -OH group in one case, and one $-\mathrm{N}=\mathrm{N}$ - group in the other. The Acid Brown 83 dye has a single amino group, with a very close $-\mathrm{NO}_{2}$ group. As mentioned previously, the proximity of other functionalities to the amino group can lead to the formation of relatively stable structures resulting in a reduced reactivity of the amino group with formaldehyde. Significant differences between both dyes (Direct Black 168 y Acid Brown 83) were not observed.

Referring to the basic dyes (Basic Brown 1 and Basic Orange 2), the Basic Orange 2 showed a greater ability to decrease the formaldehyde content than the Basic Brown 1. The structure of the Basic Brown 1 dye has four $\mathrm{NH}_{2}$ groups. Two of them can form relatively stable cyclic structures with very close $-\mathrm{N}=\mathrm{N}$ - groups with the result of 
reduced reactivity with formaldehyde. Therefore, the Basic Brown 1 dye has two completely free $\mathrm{NH}_{2}$ group to react with formaldehyde, whereas the Basic Orange 2 dye has only one completely free $\mathrm{NH}_{2}$ group. However, as mentioned above, Basic Orange 2 dye showed a greater ability for formaldehyde content reduction than Basic Brown 1 dye, even having lower number of free $\mathrm{NH}_{2}$ groups. Most likely, this is because, if the percentage of inorganic matter in dye formulations is considered (Table 2), the Basic Orange 2 dye provides the greatest amount of amino residues amenable to reaction with formaldehyde for a certain quantity of leather.

When comparing the ability of Acid Black 234 and Basic Orange 2 dyes (with similar amount of free amino residues, Table 2) in the reduction of formaldehyde content in leathers retanned with resins of high formaldehyde content (MF (B)), the Basic Orange 2 dye showed a higher ability. This could be because, as shown by thin layer chromatography (Figure 10), the Basic Orange 2 dye is mainly a single major component, while the Acid Black dye 234 is a mixture of components that can have a reduced reactivity with formaldehyde. However, further experiments are required to confirm this hypothesis or to investigate if the surface leather dyeing (Basic Orange 2 dye) have a higher influence on formaldehyde reduction than the through-dyeing (Acid Black 234 dye).

(Figure 10)

The dyestuffs considered have been taken to illustrate how their structures (presence of free amino groups, relative reactivity of these amino groups) affect the reaction with formaldehyde present in goods.

\section{Conclusions}

The ability of dyes to reduce the formaldehyde content in leather treated with formaldehyde-synthesized resins (melamine-formaldehyde and dicyandiamideformaldehyde) depends on the amount of amino groups amenable to reaction with formaldehyde. Those amino groups that in their vicinity have other functionalities (groups $-\mathrm{OH},-\mathrm{N}=\mathrm{N}-,-\mathrm{NO}_{2}$,) with which to form relatively stable structures, have a reduced reactivity with formaldehyde.

The reduction ability also depends on the formaldehyde content in leather. The lower the formaldehyde content is in leather, the greater the reduction ability. In the specific 
case of the Acid Black 234 dye, the reduction was of approximately $84 \%$ in leathers treated with melamine-formaldehyde resin of low formaldehyde content in the analysis carried out after 90 days of leather processing in front of approximately $20 \%$ when the resin was of high formaldehyde content.

As regards basic dyes, the highest reduction ability was that of the Basic Orange 2 that supplied the greatest amount of amino residues amenable to reaction with formaldehyde. When comparing the reduction ability of Acid Black 234 and Basic Orange 2 dyes (with similar amount of free amino residues), the Basic Orange 2 showed a higher ability. Most likely, this was due to that the Basic Orange 2 is mainly a single major component, while the Acid Black 234 is a mixture of components that can have a reduced reactivity with formaldehyde.

\section{Acknowledgements}

The authors are thankful to the Spanish Ministry of Economy and Competitiveness for the funding received through the CTQ2013-43029-P Project. The authors would like to thank also to Pulcra Chemicals S. L. and Trumpler Española S. A. for their help and assistance in this research and to Dr Angel Guerrero for his valuable collaboration in the interpretation of results. 


\section{References}

[1]. IULTCS. IUE-1 Document - Recommendations on cleaner technologies for leather production, www.iultcs.org/environment-iue.php; 2008 [accessed 19 Desember 2017].

[2]. UNIDO. Future trends in the World Leather and Leather Products Industry and Trade,https://leatherpanel.org/sites/default/files/publicationsattachments/future trendsin the world_leather_and leather_products industry and trade.pdf; 2010 [accessed 13 February 2018].

[3]. Novick RM, Nelson ML, McKinley MA, Anderson GL, Keenan JJ. The effect of clothing care activities on textile formaldehyde content. J Toxicol Env Heal A 2013;76(14): 883-893.

[4]. IARC Monographs. Chemical Agents and Related Occupations. Volume 100F. A review of human carcinogens, http://monographs.iarc.fr/ENG/Monographs/vol100F/mono100F.pdf; pp. 401435, 2012 [accessed 14 November 2017]

[5]. Dixit S, Yadav A, Dwivedi PD, Das M. Toxic hazards of leather industry and technologies to combat threat: a review. J Clean Prod 2015; 83: 39-49.

[6]. Thanikaivelan P, Mohan CR, Saravanabhavan S, Rao JR, Nair BU. Development of Formaldehyde-free Leathers in Perspective of Retanning. Part 1: Benchmarkig for the Evolution of a single Syntan System. J Am Leather Chem Assoc 2007; 102 (10): 306-314.

[7]. Mohan CR, Saravanabhavan S, Thanikaivelan P, Rao JR, Nair BU. Development of formaldehyde-free leathers in the perspective of retanning: Part II. Combination of formaldehyde-free retanning syntans. Clean Technol Environ Policy 2008; 10: 287 - 294. 
[8]. INESCOP. Summary of the "Mechanisms of formaldehyde formation in tanned leather and technologies for its reduction" Project, funded by IMPIVA and FEDER. November 2012. (unpublished results).

[9]. Boran S, Usta M, Gümüskaya E. Decreasing formaldehyde emission from medium density fiberboard panels produced by adding different amino compounds to urea formaldehyde resin. Int J Adhes Adhes 2011; 31: 674-8.

[10]. Costa NA, Pereira J, Ferra J, Cruz P, Martins J, Magalhaes FD, et al. Scavengers for achieving zero formaldehyde emission of wood-based panels. Wood Sci Technol 2013; 47: 1261-72.

[11]. Marsal A, Cuadros S, Ollé L1, Bacardit A, Manich AM, Font J. Formaldehyde scavengers for cleaner production: a case study focused on leather industry. $\mathrm{J}$ Clean Prod 2018; (under review)

[12]. Bayramoglu EE, Korgan A, Kalender D, Gülümser G, Okcu B, Kilic E. Elimination of Free Formaldehyde in Leather by Vinca Rosea and Camellia sinensis extracts. J Am Leather Chem Assoc 2008; 103: 119 - 122.

[13]. Bayramoglu EE. Hidden treasure of the nature: PAs: The effect of grape seeds on free formaldehyde of leather. Ind Crop Prod 2013; 41: 53 - 6.

[14]. Boran S, Usta M, Ondaral S, Gümüskaya, E.

The efficiency of tannin as a formaldehyde scavenger chemical in medium density fibreboard. Compos Pt B-Eng 2012; 43: 2487 - 91.

[15]. Marsal A, Cuadros S, Manich AM, Izquierdo F, Font J. Reduction of the formaldehyde content in leathers treated with formaldehyde resins by mean of plant polyphenols. J Clean Prod 2017; 148: 518-26.

[16]. Kirk JS. The dyeing of leather. In: O'Flaherty F, Roddy WT, Lollar RM, editors. The Chemistry and Technology of Leather. Volume III - Process control of leather quality, Florida: Krieger Publishing Company INC; 1978, p. 1-15 
[17]. EN ISO 17226-2 Standard: Determination of formaldehyde content in leather. Part 2. Quantification by colorimetric analysis; 2008

[18]. EN ISO 2419 Standard: Sample preparation and conditioning; 2012

[19]. Manich AM, Cuadros S, Font J, Bacardit A, Combalia F, Marsal A. Determination of Formaldehyde Content in Leather: EN ISO 17226 Standard. Influence of the agitation method used in the initial phase of formaldehyde extraction. J Am Leather Chem Ass 2017; 112(5): 168-79.

[20]. Cuadros S, Font J, Izquierdo F, Cuadros RM, Ollé L, Marsal A. Determination of formaldehyde content in leather: Standard EN ISO 17226, Revision and possible improvements. J Soc Leather Technol Chem 2016; 100: 167-74.

[21]. EN ISO 17226-1 Standard: Determination of formaldehyde content in leather. Part 1. Quantification by HPLC; 2008

[22]. EN ISO 4047 Standard: Determination of sulphated total ash and sulphated water insoluble ash; 1977

[23]. Mead R, Curnow RN, Hasted AM. Statistical Methods in Agriculture and Experimental Biology. $3^{\text {rd }}$ ed. New York: Chapman \& Hall/CRC; 2003 


\section{FIGURE CAPTIONS}

Figure 1. Structural formulas of the dyes studied in this work.

Figure 2. Influence of Acid Red 337 and Acid Black 234 dyes on the formaldehyde content in leathers retanned with MF (A) resin.

Figure 3. Reduction of formaldehyde content by the effect of the Acid Red 337 and Acid Black 234 dyes in leathers retanned with MF (A) resin.

Figure 4. Influence of Acid Red 337 and Acid Black 234 dyes on the formaldehyde content in leathers retanned with DCDF (A) resin.

Figure 5. Reduction of formaldehyde content by the effect of the Acid Red 337 and Acid Black 234 dyes in leathers retanned with DCDF (A) resin.

Figure 6. Influence of Acid Black 234, Direct Black 168 and Acid Brown 83 dyes on the formaldehyde content in leathers retanned with MF (B) resin.

Figure 7. Reduction of formaldehyde content by the effect of Acid Black 234, Direct Black 168 and Acid Brown 83 dyes in leathers retanned with MF (B) resin.

Figure 8. Influence of Basic Brown 1 and Basic Orange 2 dyes on the formaldehyde content in leathers retanned with MF (B) resin.

Figure 9. Reduction of formaldehyde content by the effect of Basic Brown 1 and Basic Orange 2 dyes in leathers retanned with MF (B) resin.

Figure 10. Results of the thin layer chromatography analysis for the following dyes: 1 . Acid Black 234; 2. Basic Orange 2 and 3. Basic Brown 1, by using the eluents described in Section 2.2.5. 


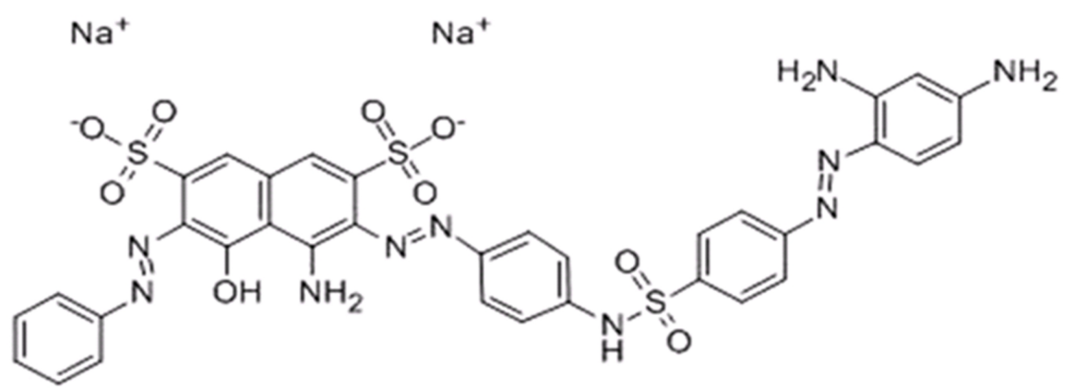

Acid Black 234 (Cl: 30027$)$

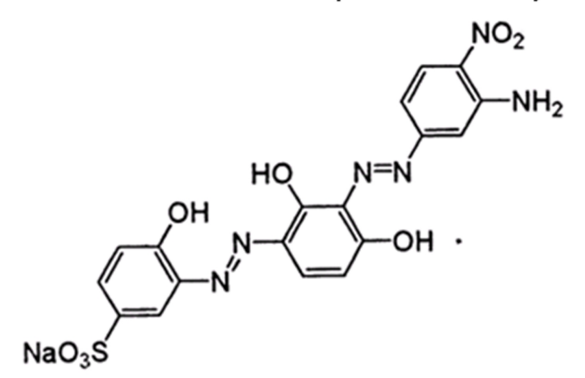

Acid Brown 83 (Cl: 20250)

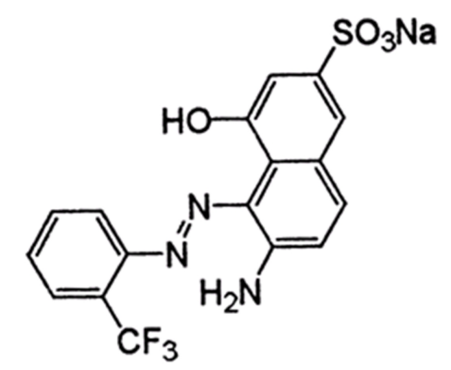

Acid Red 337 (Cl: 17102)

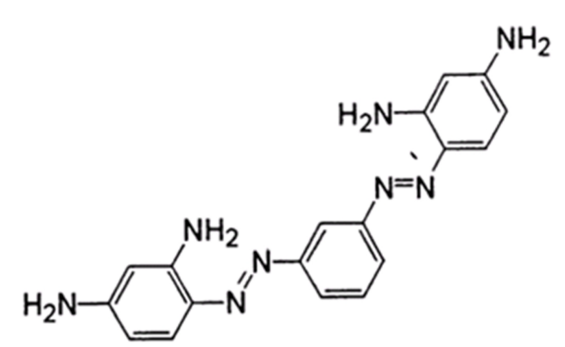

Basic Brown 1 (Cl: 21000:1)

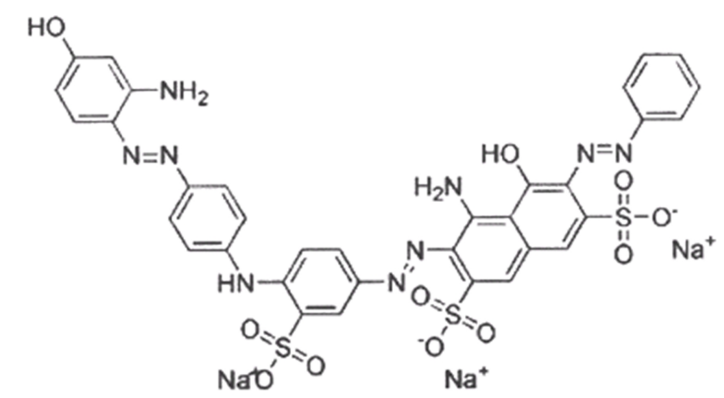

Direct Black 168 (Cl: 30420$)$

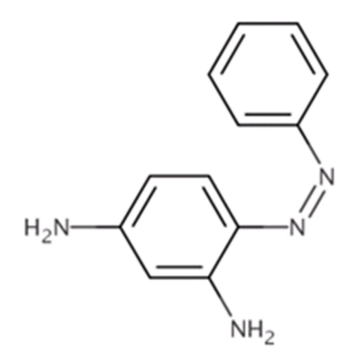

Basic Orange 2 ( $\mathrm{Cl}: 11270)$ 


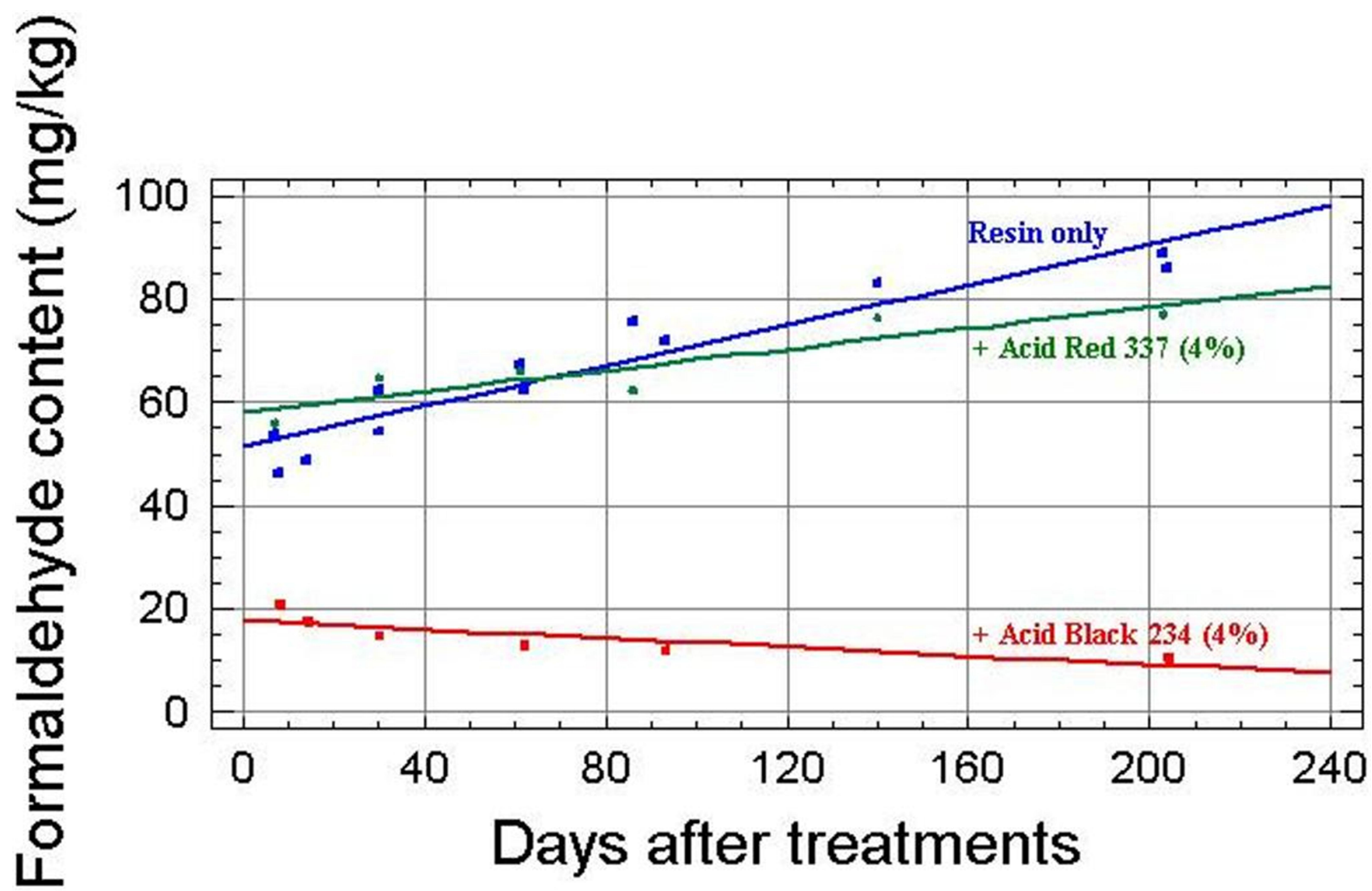




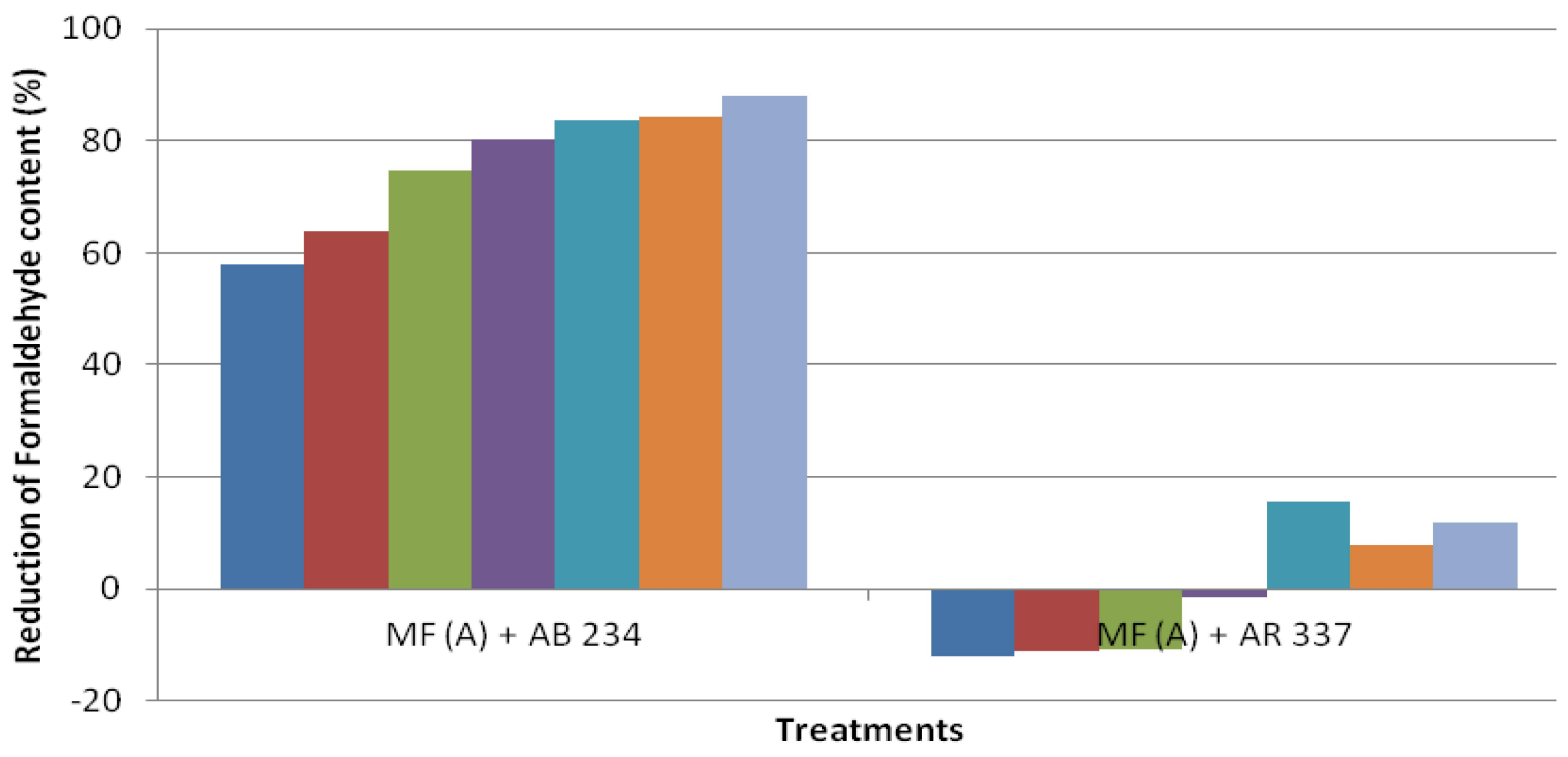

$\square 7.5$ days after treatments $\square \mathbf{1 4}$ days after treatments $\square \mathbf{3 0}$ days after treatments 61.5 days after treatments $\quad \mathbf{8 9} .5$ days after treatments $\quad 140$ days after treatments 203.5 days after treatments 


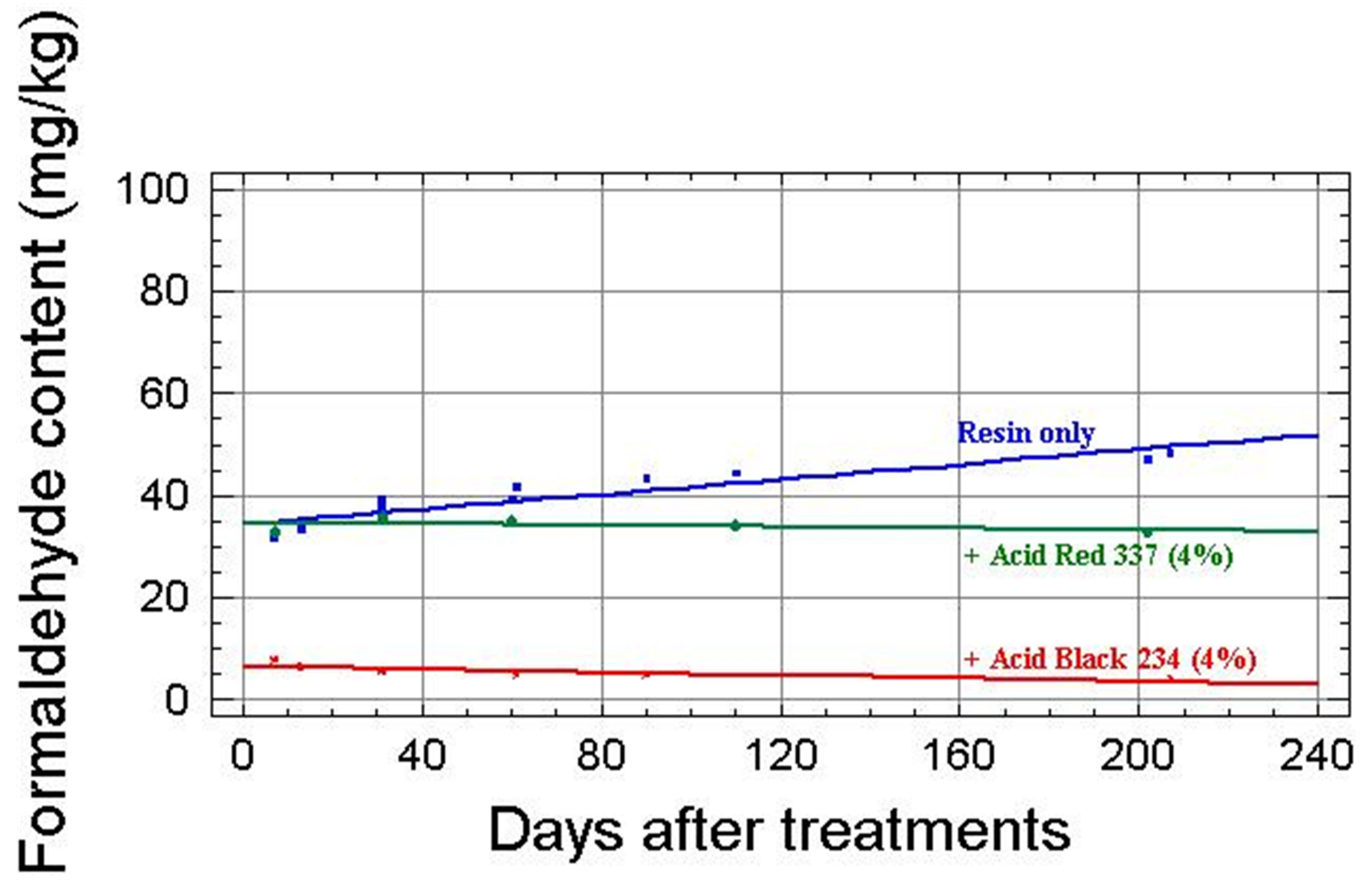




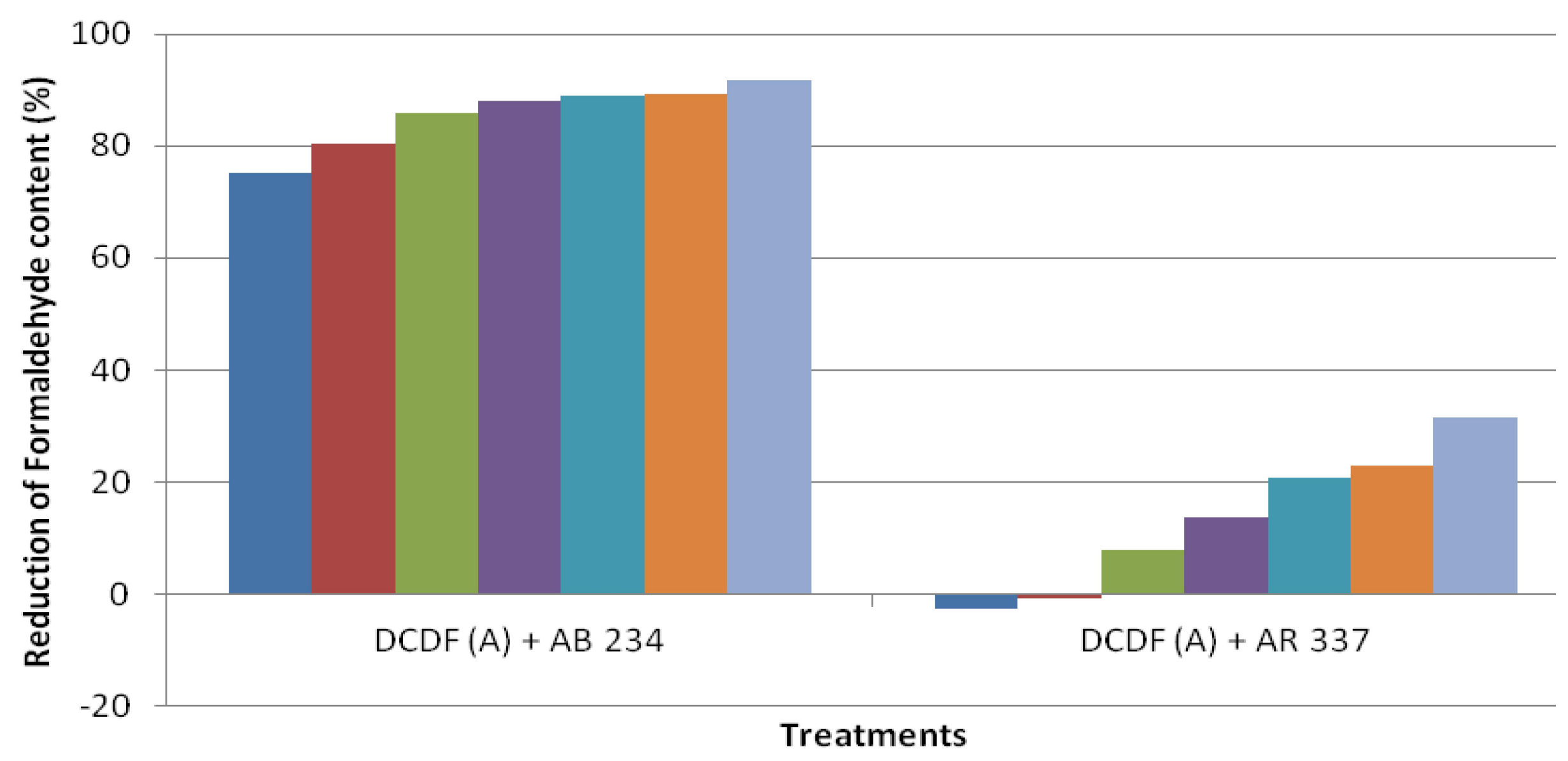

7 days after treatments

13 days after treatments

31 days after treatments

60.5 days after treatments $\quad 90$ days after treatments

110 days after treatments

204.5 days after treatments 


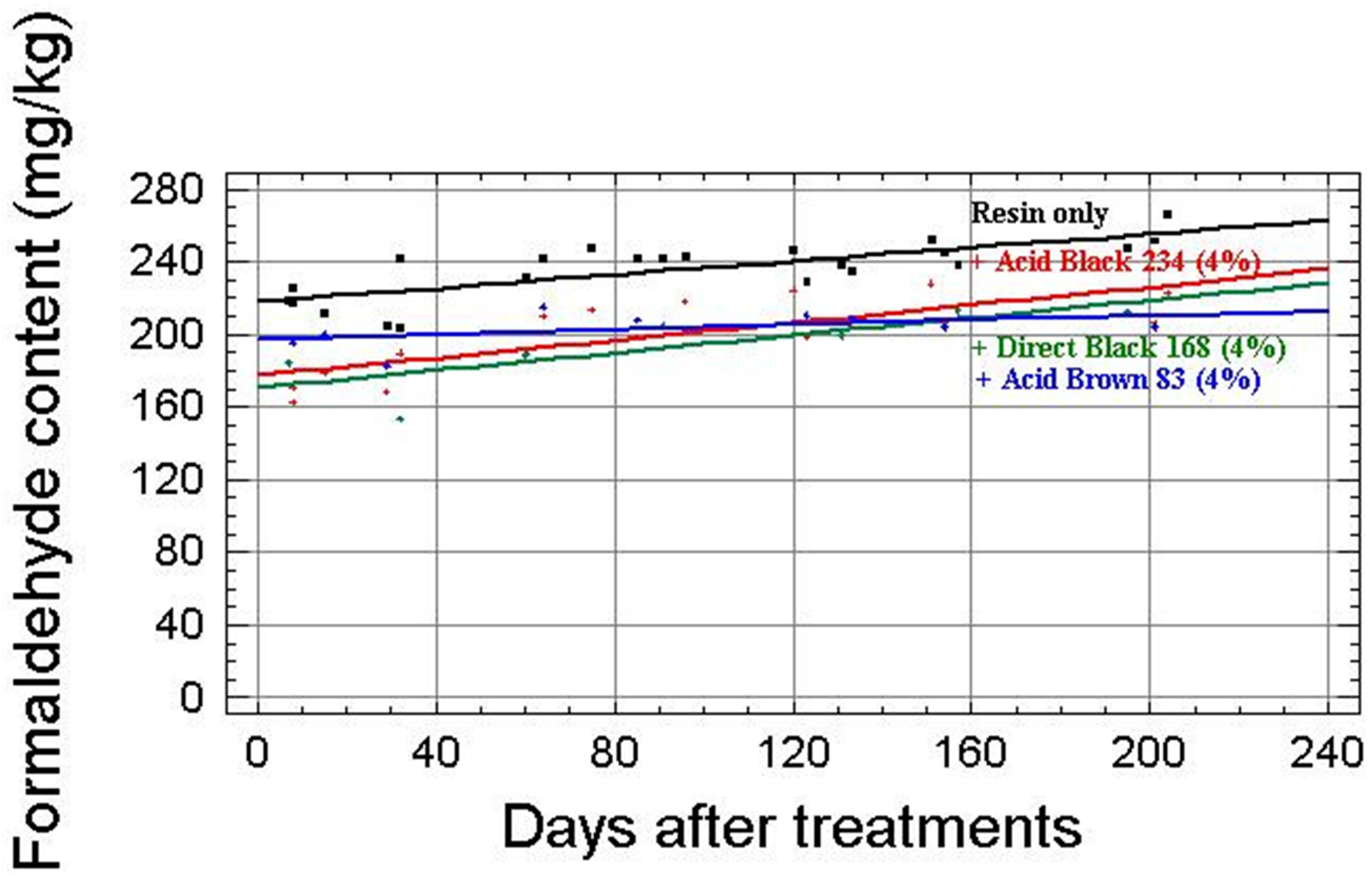




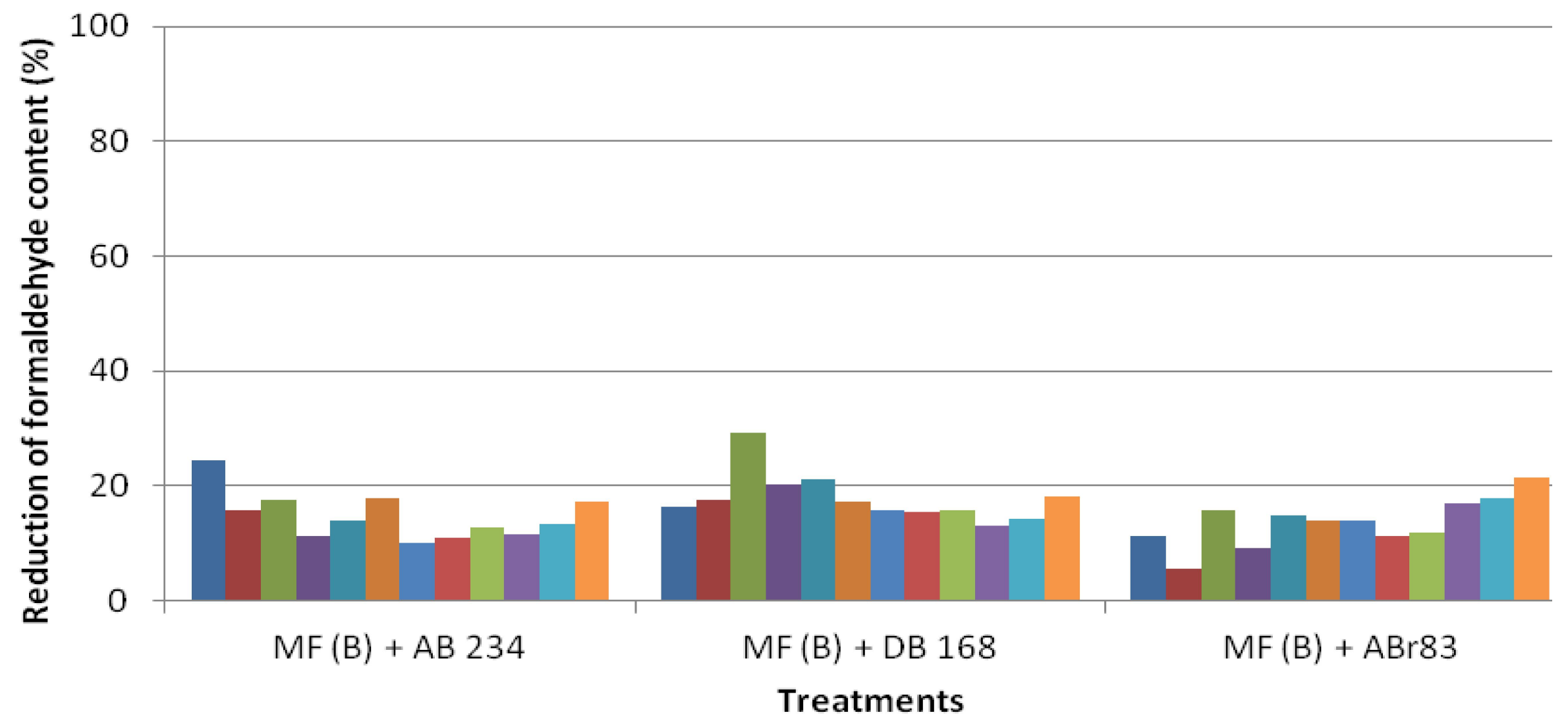

7.5 days after treatments

15 days after treatments

31 days after treatments

62 days after treatments

75 days after treatments

85 days after treatments

93.5 days after treatments

121.5 days after treatments

132 days after treatments

154 days after treatments

195 days after treatments

202.5 days after treatments 


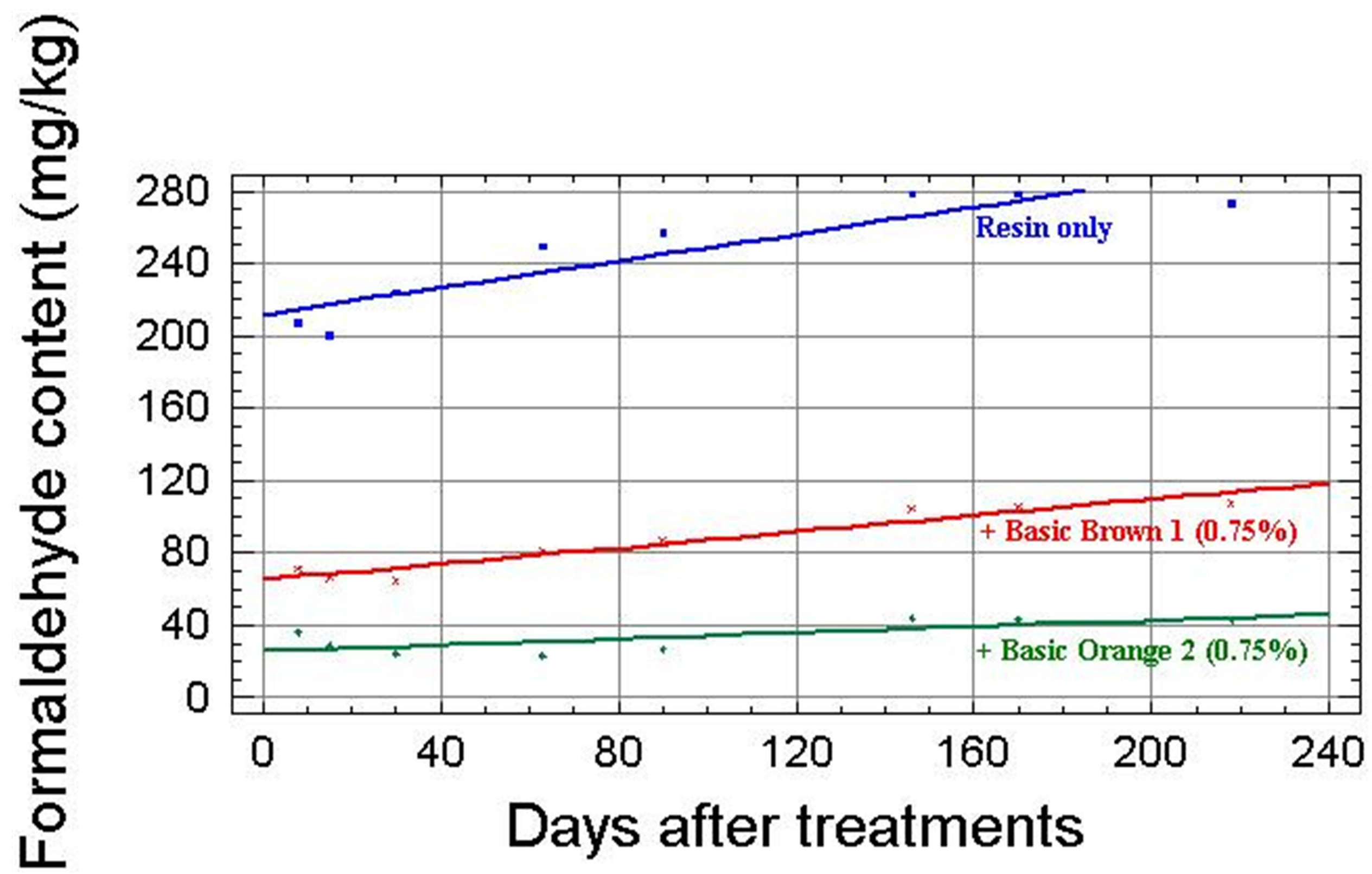




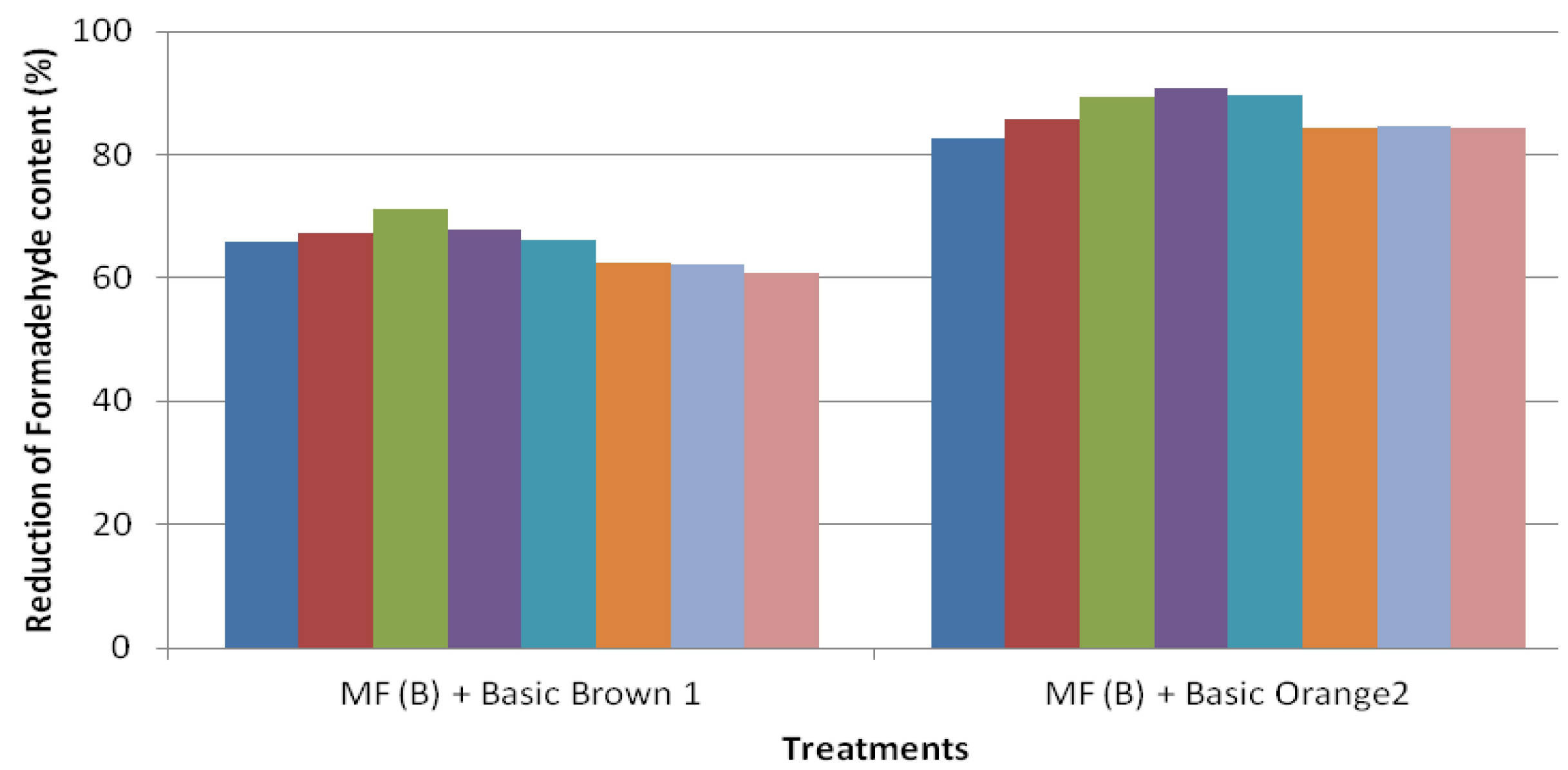

$\square$ days after treatments $\square \mathbf{1 5}$ days after treatments $\quad \mathbf{3 0}$ days after treatments 63 days after treatments $\quad 90$ days after treatments $\square 146$ days after treatments $\square 170$ days after treatments $\square 218$ days after treatments 


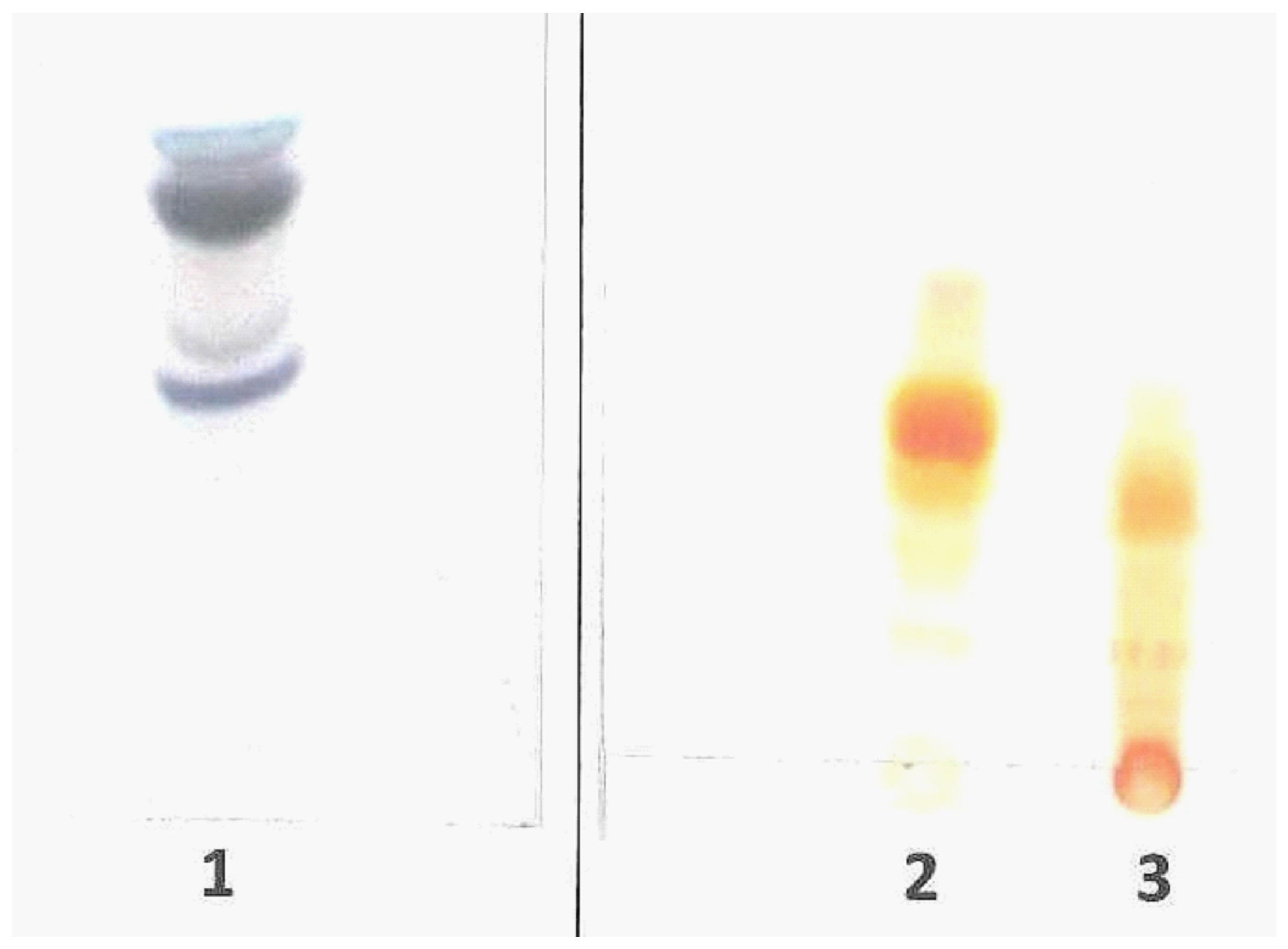


Table 1

Processing of leathers. Formulation applied.

Starting material: Butts of $1.5 \mathrm{~mm}$ wet-blue splits

All of the offers refer to the shaved wet-blue weight

\begin{tabular}{|c|c|c|c|c|c|}
\hline Process & $\%$ & Chemical & ${ }^{\circ} \mathrm{C}$ & Time & pH/remarks \\
\hline \multirow[t]{3}{*}{ Wetting } & 300 & Water & 35 & & \\
\hline & 0,3 & Formic Acid (1:10) & & & \\
\hline & 0,5 & Nonionic degreasing agent & & $60^{\prime}$ & Drain, wash good \\
\hline \multirow[t]{4}{*}{ Rechroming } & 100 & Water & 35 & & \\
\hline & 0,4 & Formic Acid (1:10) & & $10^{\prime}$ & $\mathrm{pH} 3.5$ \\
\hline & 4 & Basic Chrome sulphate 33\% & & & \\
\hline & 1 & Sodium-aluminium silicate & & $60^{\prime}$ & $\begin{array}{l}\mathrm{pH} \mathrm{4.0/4.2} \\
\text { drain, wash }\end{array}$ \\
\hline \multirow[t]{3}{*}{ Neutralization } & 150 & Water & 35 & & \\
\hline & 2 & Sodium formate & & $20^{\prime}$ & \\
\hline & 1 & Sodium bicarbonate $(1: 10)$ & & $90^{\prime}$ & $\begin{array}{l}\mathrm{pH} 5.2 / 5.4 \\
\text { check cut } \\
\text { drain, wash }\end{array}$ \\
\hline \multirow[t]{3}{*}{ Retanning } & 50 & Water & 30 & & \\
\hline & 3 & Acrylic Resin & & $60^{\prime}$ & \\
\hline & 5 & Formaldehyde resins* & & $60^{\prime}$ & \\
\hline Dyeing & 4 & Dye & & $60^{\prime}$ & \\
\hline \multirow[t]{6}{*}{ Fatliquoring } & 100 & Water & 50 & & \\
\hline & 8 & Synthetic sulphated oil & & & \\
\hline & 4 & Phosphoric ester based oil & & $60^{\prime}$ & \\
\hline & 1 & Formic Acid (1:10) & cold & $20^{\prime}$ & \\
\hline & 1 & Formic Acid (1:10) & cold & $20^{\prime}$ & \\
\hline & 1 & Formic Acid (1:10) & cold & $20^{\prime}$ & \\
\hline Washing & 150 & Water & & $3^{\prime}$ & \\
\hline \multicolumn{6}{|c|}{ Horse up (24 hours), setting out (by hand) } \\
\hline \multicolumn{6}{|c|}{$\begin{array}{l}\text { Air dry (toggle) } \\
\text { stake }\end{array}$} \\
\hline \multicolumn{6}{|c|}{ Analytical determinations } \\
\hline \multicolumn{6}{|c|}{ * Depending on the experiment, the formaldehyde resins used were: } \\
\hline \multicolumn{3}{|c|}{ Melamine-formaldehyde of low formaldehyde content: } & \multicolumn{2}{|c|}{ MF $(A)$} & \\
\hline \multicolumn{3}{|c|}{ Dicyandiamide-formaldehyde of low formaldehyde content: } & \multicolumn{2}{|c|}{$\operatorname{DCDF}(A)$} & \\
\hline \multicolumn{3}{|c|}{ Melamine-formaldehyde of high formaldehyde content: } & \multicolumn{2}{|c|}{ MF (B) } & \\
\hline
\end{tabular}


Table 2

Percentage of inorganic matter $\pm 95 \%$ confidence intervals in the studied dyes and amount of amino residues for $100 \mathrm{~g}$ of dyed leather.

\begin{tabular}{cccccc}
\hline Dye & $\begin{array}{c}\text { Offer } \\
(\%)\end{array}$ & $\begin{array}{c}\text { Inorganic } \\
\text { matter }(\%)\end{array}$ & $\begin{array}{c}\text { Total amino } \\
\text { residues/ } \\
\text { 100g leather } \\
(\mathrm{g})\end{array}$ & $\begin{array}{c}\text { Amino residues with } \\
\text { reduced reactivity/ } \\
\text { 100 g leather }(\mathrm{g})\end{array}$ & $\begin{array}{c}\text { "Free" amino } \\
\text { residues/ 100 } \\
\text { g leather }(\mathrm{g})\end{array}$ \\
\hline Basic Brown 1 & 0.75 & $38.09 \pm 0.10$ & 0.072 & 0.036 & 0.036 \\
Basic Orange 2 & 0.75 & $0.57 \pm 0.02$ & 0.096 & 0.048 & 0.048 \\
Acid Black 234 & 4.0 & $38.23 \pm 0.08$ & 0.138 & 0.092 & 0.046 \\
Direct Black 168 & 4.0 & $30.31 \pm 0,08$ & 0.099 & 0.099 & -- \\
Acid Red 337 & 4.0 & $17.89 \pm 0,01$ & 0.121 & 0.121 & -- \\
Acid Brown 83 & 4.0 & $37.07 \pm 0.06$ & 0.081 & 0.081 & -- \\
\hline
\end{tabular}




\section{Table 3}

Regression equations of formaldehyde content [FC] as a function of the number of days after treatment ND for leathers retanned with formaldehyde resins of low formaldehyde content (A), according to the equation $[\mathrm{FC}]=[\mathrm{FC}]_{0}+[\mathrm{FC}]_{\text {rate }} \times \mathrm{ND}$, including the $95 \%$ Confidence Interval for both $[\mathrm{FC}]_{0}$ and $[\mathrm{FC}]_{\text {rate }}$.

\begin{tabular}{llccc}
\hline $\begin{array}{c}\text { Regression } \\
\text { lines }\end{array}$ & \multicolumn{1}{c}{ Retanning/Dyeing Treatments } & $\begin{array}{c}{[\mathrm{FC}]_{0}} \\
(\mathbf{m g} / \mathbf{k g})\end{array}$ & $\begin{array}{c}{[\mathrm{FC}]_{\text {rate }}} \\
(\mathbf{m g} / \mathbf{k g})\end{array}$ & $\mathbf{r}$ \\
Figure 3 & MF (A) & $51.51 \pm 4.86$ & $+0.20 \pm 0.04$ & +0.95 \\
& MF (A) + Acid Black 234 (4\%) & $17.77 \pm 4.20$ & $-0.04 \pm 0.06$ & -0.81 \\
& MF (A) + Acid Red 337 (4\%) & $58.15 \pm 7.53$ & $+0.10 \pm 0.06$ & +0.90 \\
& & & & \\
Figure 5 & DCDF (A) & $34.49 \pm 2.51$ & $+0.07 \pm 0.02$ & +0.91 \\
& DCDF (A) + Acid Black 234 (4\%) & $6.67 \pm 1.53$ & $-0.02 \pm 0.03$ & -0.81 \\
& DCDF (A) + Acid Red 337 (4\%) & $34.66 \pm 3.12$ & $-0.01 \pm 0.03$ & -0.42 \\
\hline
\end{tabular}

MF: Melamine-Formaldehyde; DCDF: Dicyandiamide-Formaldehyde

$[\mathrm{FC}]_{0}$ : the initial formaldehyde content; $[\mathrm{FC}]_{\text {rate }}$ : variation of content vs. ND

$r$ : linear correlation coefficient 


\section{Table 4}

Regression equations of formaldehyde content $[\mathrm{FC}]$ as a function of the number of days after treatment ND for leathers retanned with formaldehyde resins of high formaldehyde content $(\mathrm{B})$, according to the equation $[\mathrm{FC}]=[\mathrm{FC}]_{0}+[\mathrm{FC}]_{\text {rate }} \times \mathrm{ND}$, including the $95 \%$ Confidence Interval for both $[\mathrm{FC}]_{0}$ and $[\mathrm{FC}]_{\text {rate }}$.

\begin{tabular}{llccc}
\hline $\begin{array}{c}\text { Regression } \\
\text { lines }\end{array}$ & \multicolumn{1}{c}{ Retanning/Dyeing Treatments } & $\begin{array}{c}{[\mathrm{FC}]_{0}} \\
(\mathrm{mg} / \mathrm{kg})\end{array}$ & $\begin{array}{c}{[\mathrm{FC}]_{\text {rate }}} \\
(\mathrm{mg} / \mathrm{kg})\end{array}$ & $\mathbf{r}$ \\
& MF (B) & $218.04 \pm 8.61$ & $+0.19 \pm 0.08$ & +0.76 \\
Figure 7 & MF (B) + Acid Black 234 (4\%) & $177.23 \pm 13.38$ & $+0.24 \pm 0.12$ & +0.76 \\
& MF (B) + Direct Black 168 (4\%) & $170.55 \pm 24.60$ & $+0.24 \pm 0.21$ & +0.79 \\
& MF (B) + Acid Brown 83 (4\%) & $197.28 \pm 12.39$ & $+0.07 \pm 0.11$ & +0.46 \\
& & & & \\
Figure 9 & MF (B) & $211.86 \pm 20.16$ & $+0.37 \pm 0.17$ & +0.91 \\
& MF (B) + Basic Brown 1 (0.75\%) & $65.09 \pm 7.58$ & $+0.22 \pm 0.06$ & +0.96 \\
& MF (B) + Basic Orange 2 (0.75\%) & $25.51 \pm 9.35$ & $+0.09 \pm 0.08$ & +0.73 \\
\hline
\end{tabular}

MF: Melamine-Formaldehyde;

$[\mathrm{FC}]_{0}$ : the initial formaldehyde content; $[\mathrm{FC}]_{\text {rate }}$ : variation of content vs. ND

$r$ : linear correlation coefficient 